\title{
IDENTIFICACIÓN DE RESTOS ÓSEOS DE DETENIDOS DESAPAREGIDOS Y EJEGUTADOS POLÍTICOS E INTEGRIDAD PERSONAL DE SUS FAMILIARES
}

\author{
Rocío Norambuena Avilés*
}

\begin{abstract}
Resumen
La falta de identificación de los restos óseos de quienes fueron ejecutados o desaparecidos durante la dictadura de Augusto Pinochet, imposibilita que sus familiares puedan efectuar el rito fúnebre y el proceso de duelo, vulnerando su derecho a la integridad personal. Esta tesis se fundamenta en la jurisprudencia reciente de la Corte Interamericana de Derechos Humanos y en el estudio de un relevante caso de nuestra jurisprudencia. Los tribunales de justicia deberían resolver las acciones judiciales que han sido interpuestas por los familiares de las víctimas en contra del Estado de Chile, en consideración de la vulneración del derecho a la integridad personal de los familiares. En consecuencia, la indemnización de perjuicios no puede apoyarse únicamente en la falta de servicio en que han incurrido los agentes estatales.
\end{abstract}

Palabras clave: derecho a la integridad personal, ejecutados políticos, detenidos desaparecidos, dictadura militar, derechos humanos, rito fúnebre.

\section{INTRODUGGIÓN}

Uno de los rasgos de la dictadura militar acaecida en Chile, entre el 11 de septiembre 1973 y el 11 de marzo de 1990, fue la persecución de los ciudadanos por motivos políticos. De hecho, 3.065 personas fueron ejecutadas o detenidas desaparecidas por agentes del Estado. En los últimos 25 años el Servicio Médico Legal sólo ha podido identificar los restos de 158 detenidos desaparecidos, y a la fecha faltan más de 900 casos por esclarecerse. ${ }^{1}$

Desde el punto de vista de los familiares de las víctimas, el no poder identificar los restos óseos de sus seres queridos conlleva una serie de secuelas que no se pueden disociar del patrimonio de quienes conforman la unidad familiar. Tales secuelas se derivan de las expectativas insatisfechas, y la carga familiar que implica la búsqueda

\footnotetext{
* Universidad Alberto Hurtado, Santiago, Chile (rocio.nora.aviles@gmail.com). Esta investigación ha sido patrocinada por el Museo de la Memoria y los Derechos Humanos (Concurso de Tesis 2015). Agradezco especialmente las recomendaciones de los académicos Hugo Rojas y Miriam Henríquez, y las sugerencias de los evaluadores externos. Artículo recibido el 4 de abril de 2018, aceptado para su publicación el 10 de julio de 2018.

1 LIRA (2015), p. 10.
} 
incesante de aquél cuya ausencia permanece. La falta de identificación ósea se agrava cuando se realiza de forma incorrecta por parte del Estado, lo que ha sucedido en nuestro país; ello porque conlleva una nueva vulneración del derecho a la integridad personal de los familiares de detenidos desaparecidos y ejecutados.

Esta investigación busca responder específicamente a la vulneración del derecho a la integridad personal que se manifiesta en la imposibilidad de cumplir el rito fúnebre. Debido a la importancia que tiene el rito fúnebre para los seres humanos, la imposibilidad de cumplirlo vulnera la integridad personal al dificultar el proceso de duelo. Para corregir esta situación se requiere la correcta identificación de los restos de los ejecutados políticos y desaparecidos, para luego entregar sus cuerpos a sus familiares. La Corte Interamericana de Derechos Humanos (Corte IDH) ha establecido que la ubicación, traslado y exhumación de restos mortales es una forma de reparación para los familiares. ${ }^{2}$ Se considera que existe una vulneración de la integridad personal de los familiares de detenidos desaparecidos y ejecutados políticos, cuyos cuerpos no han sido encontrados. La ausencia de las osamentas de sus parientes les impide realizar un proceso propio de las culturas humanas: ${ }^{3}$ el rito fúnebre. Como se verá más adelante, se trata de un problema secuencial: $1^{\circ}$ ) la falta de identificación de los restos de ejecutados en dictadura impide que sean entregados a sus familias. $2^{\circ}$ ) El no contar con las osamentas de sus parientes impide que estas personas completen el rito fúnebre. $3^{\circ}$ La imposibilidad de concretar el rito fúnebre, al ser éste un proceso fundamental para nuestra especie, vulnera la integridad personal de quienes son familiares de detenidos y ejecutados en dictadura, cuyos cuerpos no han sido entregados. Dada la relación que existe entre la falta de identificación de restos óseos de detenidos desaparecidos y ejecutados políticos y el derecho a la integridad personal de sus familiares, es posible sostener que realizándose las diligencias conducentes a la correcta identificación de las víctimas a través de pruebas de ADN, se contribuye al restablecimiento de la integridad personal de sus familiares.

\section{EL DEREGHO A LA INTEGRIDAD PERSONAL DE LOS FAMILIARES DE EJEGUTADOS Y DESAPAREGIDOS}

\subsection{El concepto de derecho a la integridad personal}

Según María Isabel Afanador, por derecho a la integridad personal puede entenderse al "conjunto de condiciones psíquicas, físicas y morales que le permiten al ser humano su existencia, sin sufrir ningún tipo de menoscabo en cualquiera de estas

2 Humberto Sánchez vs. Honduras (2003); Caso Goiburú y otros vs. Paraguay (2006).

3 Tal como señala el antropólogo Donald E Brown, autor de Human Universals, uno de los universales culturales son los ritos de paso y entre estos encontramos los ritos funerarios o mortuorios. El concepto de "universales culturales" se refiere a un fenómeno observable que se encuentra presente en todas las personas, culturas y sociedades humanas a lo largo de la historia. Basado en ello, es posible afirmar que si los ritos mortuorios se señalan como universales culturales, están presentes en todas las culturas y sociedades, siendo un proceso fundamental para las personas. 
tres dimensiones". ${ }^{4}$ En el mismo sentido, Claudio Nash sostiene que "este derecho no sólo dice relación con la integridad física, sino que también abarca otros aspectos como la psíquica y moral. " ${ }^{\circ}$ En cuanto a su dimensión física, Afanador afirma que "la integridad física hace referencia a la plenitud corporal del individuo; de allí que toda persona tiene derecho a ser protegida contra agresiones que puedan afectar o lesionar su cuerpo, sea destruyéndola o causándole dolor físico o daño a su salud". ${ }^{6}$ En cuanto a su dimensión psíquica, sostiene que "la integridad psíquica y moral se concreta en la plenitud de facultades morales, intelectuales y emocionales". ${ }^{7} \mathrm{El}$ derecho a la integridad psíquica es el derecho que tienen todas las personas a no ser sometidas a tratos que causen un daño en su esfera emocional y moral. En el tema bajo estudio, la vulneración principal se produce precisamente en la esfera psico-emocional de los afectados porque la desaparición de los parientes genera sufrimiento y angustia en sus familiares, además de desesperación, impotencia e inseguridad ante la negativa de las autoridades a investigar los hechos ${ }^{8}$. La Corte IDH ha sostenido una concepción amplia de la integridad personal, tal como queda de manifiesto en su razonamiento en el Caso Familia Barrios vs. Venezuela:

La infracción del derecho a la integridad física y psíquica de las personas es una clase de violación que tiene diversas connotaciones de grado y que abarca desde la tortura hasta otro tipo de vejámenes o tratos crueles, inhumanos o degradantes, cuyas secuelas físicas y psíquicas varían de intensidad según los factores endógenos y exógenos que deberán ser demostrados en cada situación concreta. Es decir, las características personales de una supuesta víctima de tortura o tratos crueles, inhumanos o degradantes, deben ser tomadas en cuenta al momento de determinar si la integridad personal fue vulnerada, y por ende, incrementar el sufrimiento y el sentido de humillación cuando son sometidas a ciertos tratamientos. Asimismo, el Tribunal ha indicado que todo uso de la fuerza que no sea estrictamente necesario por el propio comportamiento de la persona detenida constituye un atentado a la dignidad humana en violación del artículo 5 de la Convención Americana. ${ }^{9}$

\subsection{El reconocimiento del derecho a la integridad personal}

La integridad personal se encuentra consagrada en el art. $5^{\circ}$ de la Convención Americana sobre Derechos Humanos (conocida como Pacto de San José de Costa Rica). En su primer inciso, dicha norma dispone lo siguiente: "Toda persona tiene derecho a que se respete su integridad física, psíquica y moral". ${ }^{10}$ En 1969, el Gobier-

\footnotetext{
4 Afanador (2002), p. 147.

5 NASH (2014), p. 135.

6 Afanador (2002), p. 147.

7 Afanador (2002), p. 148.

8 Blake vs. Guatemala (1998), párrafo 114.

9 Familia Barrios vs. Venezuela (2011), párrafo 52.

10 Convención Americana sobre Derechos Humanos (1969).
} 
no de Chile suscribió dicha Convención, aunque recién en 1990 el instrumento de ratificación fue depositado en la Secretaría General de la Organización de los Estados Americanos (OEA). El Decreto n 873 del Ministerio de Relaciones Exteriores aprobó la Convención Americana sobre Derechos Humanos en los siguientes términos:

a) El Gobierno de Chile declara que reconoce la competencia de la Comisión Interamericana de Derechos Humanos, por tiempo indefinido y bajo condiciones de reciprocidad, para recibir y examinar las comunicaciones en que un Estado Parte alegue que otro Estado Parte ha incurrido en violaciones de derechos humanos establecidos en la Convención Americana sobre Derechos Humanos, en los términos previstos en el artículo 45 de la mencionada Convención.

b) El Gobierno de Chile declara que reconoce como obligatoria de pleno derecho la competencia de la Corte Interamericana de Derechos Humanos respecto de los casos relativos a la interpretación y aplicación de esta Convención de conformidad con lo que dispone su artículo 62. ${ }^{11}$

En consecuencia, el Estado de Chile ha reconocido expresamente la competencia de la Comisión Interamericana de Derechos Humanos (Comisión IDH) para investigar eventuales violaciones a los derechos humanos. Además se reconoce como obligatoria y de pleno derecho la competencia de la Corte IDH para conocer de las alegaciones por violaciones a los derechos humanos, aplicando e interpretando la Convención cuando fuere necesario. Además, debe tenerse presente que el Art. $5^{\circ}$, inciso $2^{\circ}$, de la Constitución Política señala que: "El ejercicio de la soberanía reconoce como limitación el respeto a los derechos esenciales que emanan de la naturaleza humana. Es deber de los órganos del Estado respetar y promover tales derechos, garantizados por esta Constitución, así como por los tratados internacionales ratificados por Chile y que se encuentren vigentes." Como se puede apreciar, en nuestra carta fundamental se reconocen expresamente como derechos fundamentales (DDFF) que limitan el ejercicio de la soberanía aquéllos que se encuentran garantizados en tratados internacionales ratificados por Chile. Tal es el caso de la citada Convención, siendo posible afirmar que el derecho a la integridad personal forma parte del catálogo de derechos vigentes en nuestro ordenamiento jurídico. ${ }^{12}$

Por otra parte, en nuestro ordenamiento constitucional es posible identificar la protección de la integridad psíquica y física de la persona en el Capítulo referido a las garantías constitucionales. El Art. 19 señala que la Constitución asegura a todas las personas: " 1 . El derecho a la vida y a la integridad física y psíquica de la persona." Nuestra doctrina ha señalado que tal derecho comprende la "esfera de inmunidad y de abstención, que conlleva una prohibición estatal y respecto de particulares frente

11 Decreto No 873 (1991).

12 En cuanto a la relación entre derecho nacional e internacional me remito a lo expuesto por el profesor Humberto Nogueira en Nogueira (2007). 
a interferencias ilegítimas en el organismo y la psiquis de la persona". ${ }^{13}$ En cuanto al derecho a la integridad psíquica, se entiende por tal al derecho que tiene toda persona para evitar que un tercero le cause daño emocional, una aflicción o un dolor moral.

La jurisprudencia ha recibido el derecho a la integridad psíquica en nuestro ordenamiento jurídico, contando con suficiente aceptación en la medida que se conecta con otros DDFF. Así lo ha sostenido el Tribunal Constitucional al referirse a la constitucionalidad de una acción de reclamación de paternidad, en la cual se han vinculado el derecho a la honra de la familia con el derecho a la integridad psíquica. ${ }^{14}$ En el ámbito del derecho de familia, y a propósito de situaciones de violencia intrafamiliar, la jurisprudencia ha establecido que la violencia psicológica que ejerce uno de los cónyuges sobre el otro implica una vulneración a la integridad psíquica de la víctima. ${ }^{15}$ También la jurisprudencia ha dispuesto que el acoso implica una vulneración a la integridad psíquica. ${ }^{16}$ En materia de educación se ha hecho referencia a la vulneración a la integridad psíquica que deriva de la imposibilidad de asistir a clases por la "toma" de un establecimiento educacional. ${ }^{17}$ Finalmente, la jurisprudencia laboral ha reconocido esta garantía fundamental, estimándose que los despidos injustificados, el mobbing y los maltratos en el lugar de trabajo vulneran la integridad psíquica del trabajador. ${ }^{18}$

En consecuencia, el derecho a la integridad personal se encuentra reconocido en el Pacto de San José de Costa Rica (Art. $5^{\circ}$ ), en la Constitución Política (Arts. $5^{\circ}$ y $19 \mathrm{n}^{\circ}$ 1), y en la jurisprudencia. Claro que la integridad personal como concepto propio del derecho internacional de los derechos humanos es más amplio que la integridad psíquica y física contenida en la Constitución. Sin embargo, el primer concepto se incorpora a nuestro ordenamiento por la vía del Art. $5^{\circ}$, inciso segundo, de la Constitución.

\subsection{Integridad personal y familiares de víctimas de violaciones a los derechos humanos}

La Corte IDH ha señalado, en diversas oportunidades, que los familiares de las víctimas de violaciones de los derechos humanos pueden ser, a su vez, víctimas. ${ }^{19}$ Ello es una importante consecuencia de la visión amplia de integridad personal que ha sido acogida por la Corte. La Corte ha ampliado el alcance de este derecho en el

13 García y Contreras (2014), p. 293.

14 Muñoz c/Muñoz (2009).

15 Villegas Paillán c/ Georgia Diaz (2010).

16 Caicheo Barrientos c/Pérez Santana (2012).

17 Llaguel Figueroa y otros c/Ilustre Municipalidad de Santiago y otros (2014).

18 A modo de ejemplo, vid. Zapata con Taleb (2015); Gómez con Universidad de la República (2009); Rivera con Vida Tres (2010).

19 Blake vs. Guatemala, (1998); Villagrán Morales y otros vs. Guatemala (1999); Castillo Páez vs. Perú, (1997) 
sentido que ciertas violaciones de derechos humanos (DDHH) producen un impacto en la persona de los familiares de las víctimas. Esto se puede apreciar en el razonamiento que hace la Corte en el caso Aloeboetoe vs. Surinam. ${ }^{20}$ También se puede apreciar esta mirada más amplia en la forma en que el Estado debe tratar a los familiares de víctimas de ciertas violaciones graves de derechos humanos. Por ejemplo, en los casos de desaparición forzada de personas, los familiares de los desaparecidos son considerados víctimas directas de una violación al derecho a la integridad personal. ${ }^{21}$ Como se puede apreciar, para la Corte IDH es vital la forma en que son tratados los derechos de los familiares de las personas desaparecidas.

El caso Kawas Fernández vs. Honduras presenta un valioso aporte para el concepto de integridad personal pues en su decisión la Corte establece que el trato que reciben los familiares de una víctima de violaciones de DDHH por parte del Estado puede transformarlos en víctimas directas de la violación a su integridad personal. Si bien hay una violación concreta de DDHH respecto de sus familiares; el trato que dé el Estado a esta situación podría implicar que ellos también sean víctimas, toda vez que se ve afectada su integridad personal. Por ejemplo, si los familiares denuncian la desaparición forzada de uno de sus parientes - quien sería la víctima directa por la afectación de su libertad ambulatoria- y el Estado hace caso omiso a dicha denuncia. Lo anterior, porque la angustia y el miedo generado por la ausencia del pariente implica una vulneración a la dimensión psíquica y moral de la integridad personal.

La Corte IDH distingue en el caso Kawas Fernández vs. Honduras dos categorías de personas cercanas a las víctimas de violaciones a los DD.HH. y que pueden ser consideradas como víctimas de la violación de su derecho a la integridad personal: los familiares directos de las víctimas, y las personas que tienen un vínculo particularmente estrecho con la víctima. Respecto de la primera categoría, la Corte señala:

En varias oportunidades, la Corte Interamericana ha declarado la violación del derecho a la integridad personal de familiares de víctimas de ciertas violaciones de los derechos humanos u otras personas con vínculos estrechos con aquellas. Al respecto, en el Caso Valle Faramillo y otros vs. Colombia este Tribunal consideró que se puede declarar la violación del derecho a la integridad psíquica y moral de familiares directos de víctimas de ciertas violaciones de derechos humanos aplicando una presunción iuris tantum respecto de madres y padres, hijas e hijos, esposos y esposas, compañeros y compañeras permanentes (en adelante "familiares directos"), siempre que ello responda a las circunstancias particulares en el caso. En el caso de tales familiares directos, corresponde al Estado desvirtuar dicha presunción. ${ }^{22}$

20 Aloeboetoe y otros vs. Surinam (1993).

21 Kawas Fernández vs. Honduras (2009); NASH (2014), p. 135.

22 Kawas Fernández vs. Honduras (2009). 
En cuanto a la segunda categoría, ha sostenido:

En los demás supuestos, el Tribunal deberá analizar si de la prueba que consta en el expediente se acredita una violación del derecho a la integridad personal de la presunta víctima, sea o no familiar de alguna otra víctima en el caso. Respecto de aquellas personas sobre quienes el Tribunal no presumirá una afectación del derecho a la integridad personal por no ser familiares directos, la Corte evaluará, por ejemplo, si existe un vínculo particularmente estrecho entre éstos y las víctimas del caso que permita a la Corte declarar la violación del derecho a la integridad personal. El Tribunal también podrá evaluar si las presuntas víctimas se han involucrado en la búsqueda de justicia en el caso concreto, o si han padecido un sufrimiento propio como producto de los hechos del caso $\mathrm{o}$ a causa de las posteriores actuaciones u omisiones de las autoridades estatales frente a los hechos. ${ }^{23}$

Otro caso relevante es Blake vs. Guatemala. En su decisión la Corte IDH dispuso lo siguiente:

Esta cuestión que plantea la Comisión, sólo puede ser examinada en relación con los familiares del señor Nicholas Blake, ya que la violación de la integridad psíquica y moral de dichos familiares, es una consecuencia directa de su desaparición forzada. Las circunstancias de dicha desaparición generan sufrimiento y angustia, además de un sentimiento de inseguridad, frustración e impotencia ante la abstención de las autoridades públicas de investigar los hechos. ${ }^{24}$

A propósito de este tema, la Corte Europea de Derechos Humanos ha establecido que cuando se violan DDFF de una persona, tales como el derecho a la vida o el derecho a la integridad física, las personas más cercanas a la víctima también pueden ser consideradas como víctimas. Se desarrolló aún más el concepto, resaltando que entre los factores a ser considerados se encuentran: la proximidad del vínculo familiar -si se trata de hijos, padres, hermanos, etc.-, las circunstancias particulares de la relación con la víctima, el grado en el cual el familiar fue testigo de los eventos relacionados con la desaparición, la forma en que el familiar se involucró respecto a los intentos de obtener información sobre la desaparición de la víctima y la respuesta ofrecida por el Estado a las gestiones incoadas. ${ }^{25}$

A partir de la jurisprudencia de la Corte IDH, y en relación con la jurisprudencia de la Corte Europea de Derechos Humanos, es posible concluir que las vulneraciones a los DDFF de las personas afecten la integridad personal de sus parientes. Ello es especialmente importante en los casos de desapariciones forzadas en que la afectación a la integridad psíquica y moral causada por la preocupación y el miedo por el pariente desaparecido es fácilmente perceptible.

23 Kawas Fernández vs. Honduras (2009).

24 Blake vs. Guatemala (1998), párrafo 114.

25 Timurtas v. Turkey, (2000); Çakici v. Turkey (1999). 


\section{INTEGRIDAD PERSONAL, AUSENGIA DEL GUERPO Y RITO FÚNEBRE}

\subsection{Duelo, rito fúnebre e integridad personal}

El proceso de duelo, y su exteriorización a través del luto, es fundamental en todas las culturas. Es normal que las personas sientan añoranza por sus seres queridos que ya no los acompañan, sea por su muerte o su desaparición. También el duelo puede ser un asunto de carácter colectivo, cuando un grupo social o una comunidad determinada han perdido a uno de sus integrantes. Si se parte del supuesto que el proceso de duelo es propio del ser humano, natural y necesario, la imposibilidad de realizarlo conlleva a una afectación a la integridad personal del sujeto. La muerte de un sujeto puede ser mirada desde dos puntos de vista: por un lado, refiriéndose al individuo que ha fallecido y, por otro, desde la perspectiva de los deudos, es decir, de aquellos que sobreviven a la muerte pero que sufren la ausencia del que ya partió. La muerte es el factor que gatilla la transformación de familiares -hijos, padres, cónyuge- en deudos, esto es, de quienes experimentan el proceso de duelo.

Diversos autores coinciden al sostener que el duelo es aquel "proceso psíquico necesariamente elaborado y vivido por el deudo tras una muerte cercana, con el fin de ser el espacio establecido para transformar el dolor en dulce añoranza" ${ }^{26}$ En Los Ritos de Paso (1909), Van Gennep define al luto como aquel "estado de margen para los supervivientes, en el que entran mediante ritos de separación y del que salen mediante ritos de reintegración a la sociedad general". ${ }^{27}$ En consecuencia, con la muerte del ser querido los familiares entran en un proceso de duelo, el cual se manifiesta públicamente mediante el luto y del cual salen por medio de ritos de reintegración a la sociedad. Junto al duelo y al luto, como fenómenos relacionados a la muerte del otro, se encuentran los rituales funerarios. Estos rituales se dan en todas las culturas desde tiempos inmemoriales. Según Louis-Vincent Thomas, estos rituales pueden darse en relación al elemento aire - por ejemplo, torres del silencio, dejar los cuerpos sobre árboles, a ras de la superficie--, tierra - al enterrar al fallecido-, agua -como los marineros que antiguamente arrojaban el cuerpo al mar o como es costumbre en la India sumergir el cuerpo en el río Ganges- y fuego - por ejemplo, la cremación ${ }^{28}$. En las sociedades occidentales los ritos más comunes para el caso de la muerte son el entierro y la cremación. Desde sus orígenes como disciplina a comienzos del siglo XX, la Antropología ha mostrado que el rito fúnebre es practicado de diversas maneras en todas las culturas pre modernas, por lo que bien puede afirmarse que se trata de un rito fundamental para las personas. ${ }^{29}$ Philippe Ariés ha explicado la relevancia que revisten las tumbas en la cultura occidental "[Las] tumbas se convertían en el signo

26 SuÁrez (2011), p. 53.

27 VAn Gennep, (2008), p 205.

28 Thomas (1985).

29 Tal como se ha mencionado en la nota a pie de página $n^{\circ} 3$ en atención a lo expuesto por Donald $E$ Brown. En el mismo sentido Ariés (2000) y Thomas (1983). 
de su presencia más allá de la muerte. [...] esta presencia era una respuesta al afecto de los supervivientes y a su nueva repugnancia por aceptar la desaparición del ser querido. La gente se aferra a sus restos". ${ }^{30}$

Puede sostenerse que duelo, luto y rito fúnebre son interdependientes. La realización del rito fúnebre gatilla el proceso de duelo, el cual se exterioriza en el luto. La posibilidad de realizar el rito fúnebre -ya sea entierro, cremación, sumergir el cuerpo, etc.- permite al individuo iniciar el proceso de duelo. Para poder informar al resto de la comunidad que se encuentra en dicho proceso, normalmente se recurre a símbolos como el luto. De manera paulatina la persona que vive el duelo logra calmar en parte su dolor y reintegrarse a la sociedad. Esta interdependencia nos muestra lo gravitante que es para los deudos el hecho de realizar el rito fúnebre. Si este no se puede llevar a cabo, en tanto condición del proceso de duelo y luto, entonces se suspende la aceptación de la partida del ser amado y con ello el bienestar psicológico y emocional.

Existe una relación entre la posibilidad de llevar a cabo el proceso de duelo con normalidad y la integridad personal. Como se ha mencionado, el duelo permite a los deudos sanar, al transformar el dolor en dulce añoranza. Si el rito fúnebre y el duelo no son posibles de llevar cabo o no se pueden verificar por la actuación de terceros, entonces se estaría vulnerando la integridad personal de los individuos. En el caso de los familiares de detenidos desaparecidos, quienes no han recibido las osamentas de sus parientes, es plausible afirmar que: $1^{\circ}$ ) al no recibir las osamentas de sus parientes, no pueden efectuar ritual mortuorio alguno; $2^{\circ}$ ) al no poder realizar dichos rituales, no pueden pasar con normalidad por el proceso de duelo; $3^{\circ}$ ) lo cual implica una perturbación psicológica, vulnerándose la integridad personal.

\subsection{Jurisprudencia internacional}

En el apartado anterior se intentó familiarizar al lector con el rito fúnebre, señalando su concepto, formas y su importancia en las diversas culturas. Ya establecida su importancia, se procederá a analizar el trato que se ha dado a los ritos mortuorios y a la integridad personal de los deudos en la jurisprudencia de la Corte Interamericana.

Como única prevención, debe señalarse que en los casos que se revisan a continuación la Corte no trata especialmente la falta de rito fúnebre pero su análisis es relevante toda vez que ha reconocido el vínculo que existe entre una digna sepultura y la integridad personal de los familiares del fallecido; afirmando que la imposibilidad de llevar a cabo el proceso de duelo vulnera la integridad personal de los deudos por agravar el sufrimiento padecido por la previa desaparición.

En el denominado caso "Niños de la Calle"(Villagrán Morales y otros vs. Guatemala), la Corte IDH conoció el caso de cinco jóvenes que vivían en la calle en Guatemala: Henry Giovanni Contreras, Federico Clemente Figueroa Túnchez, Julio Roberto

30 ARIÉs (2000), p 74. 
Caal Sandoval, Jovito Josué Juárez Cifuentes y Anstraum Aman Villagrán Morales. El 15 de junio de 1990 los jóvenes fueron secuestrados por hombres armados, y subidos a un vehículo. Posteriormente sus cadáveres fueron encontrados en los Bosques de San Nicolás, con evidentes muestras corporales de haber sufrido malos tratos y con señales de balas en sus cráneos. Los familiares de los jóvenes solicitaron ayuda a las autoridades de la época. Sin embargo, fueron objeto de amenazas. Concluida la investigación, se determinó que los jóvenes habían muerto por el accionar de agentes de las fuerzas de seguridad del Estado. La Corte IDH, en su sentencia pronunciada el 19 de noviembre de 1999, sostuvo los parientes inmediatos de los niños de la calle eran víctimas, toda vez que el desaparecimiento de los jóvenes y el posterior descubrimiento de sus cadáveres implicaba una violación a la integridad personal. En su considerando 173 la Corte establece que:

[...] las autoridades no hicieron esfuerzos adecuados para localizar a los parientes inmediatos de las víctimas, notificarles la muerte de éstas, entregarles los cadáveres y proporcionarles información sobre el desarrollo de las investigaciones. El conjunto de esas omisiones postergó y, en algunos casos, negó a los familiares la oportunidad de dar a los jóvenes una sepultura acorde con sus tradiciones, valores o creencias y, por lo tanto, intensificó sus sufrimientos. A ello se agrega el sentimiento de inseguridad e impotencia que le causó a esos parientes la abstención de las autoridades públicas en investigar a cabalidad los correspondientes delitos y castigar a sus responsables. ${ }^{31}$

Luego, en el considerando 174, la Corte señala que el inadecuado trato que se da a los restos de las víctimas, es una vulneración a sus deudos:

La Corte debe destacar entre las conductas de los agentes estatales que intervinieron en los hechos del caso y que produjeron un impacto sobre sus familiares, la correspondiente al tratamiento que se dio a los cuerpos de los jóvenes cuyos cadáveres aparecieron en los Bosques de San Nicolás. Estas personas no sólo fueron víctimas de la violencia extrema correspondiente a su eliminación física, sino que, además, sus cuerpos fueron abandonados en un paraje deshabitado, quedaron expuestos a las inclemencias del tiempo y a la acción de los animales y hubieran podido permanecer así durante varios días, si no hubieran sido encontrados fortuitamente. En el presente caso, es evidente que el tratamiento que se dio a los restos de las víctimas, que eran sagrados para sus deudos y, en particular, para sus madres, constituyó para éstas un trato cruel e inhumano. ${ }^{32}$

Otro ejemplo es el caso Blake versus Guatemala; en 1985, el periodista estadounidense Nicholas Blake fue detenido por la Patrulla Civil de El Llano, en virtud de las órdenes directas del personal de la guarnición de Las Majadas del Ejército de Guatemala. $\mathrm{Al}$ igual que en el caso anterior, la Corte IDH determinó que los familiares de

31 Villagrán Morales y otros vs. Guatemala (1999).

32 Villagrán Morales y otros vs. Guatemala (1999). 
las víctimas a violaciones de DDHH pueden ser, a su vez, víctimas. “...la violación de la integridad psíquica y moral de dichos familiares, es una consecuencia directa de su desaparición forzada. Las circunstancias de dicha desaparición generan sufrimiento y angustia, además de un sentimiento de inseguridad, frustración e impotencia ante la abstención de las autoridades públicas de investigar los hechos". ${ }^{33}$

Cuando alguna circunstancia impide la entrega del cuerpo, se imposibilita la realización del rito fúnebre; el cuerpo de Nicholas Blake fue incinerado por agentes estatales con la finalidad de imposibilitar su hallazgo y reconocimiento. Al respecto la Corte determinó que:

[...] la incineración de los restos mortales del señor Nicholas Blake, para destruir todo rastro que pudiera revelar su paradero, atenta contra los valores culturales, prevalecientes en la sociedad guatemalteca, transmitidos de generación a generación, en cuanto al respeto debido a los muertos. Esta acción intensificó el sufrimiento de los familiares del señor Nicholas Blake. ${ }^{34}$

Finalmente en el caso Bámaca Velásquez vs Guatemala, la Corte sostuvo que se vulneraron los derechos de los familiares de detenidos desaparecidos atentándose contra su integridad personal cuando la desaparición de un ser querido provoca angustia, o no siendo posible darle una digna sepultura al fallecido,

[...] el Estado violó el derecho a la integridad personal de la familia de Bámaca Velásquez como resultado de "las angustias y los sufrimientos que padecieron como consecuencia de la desaparición forzada de Efraín Bámaca Velásquez". La incertidumbre generada por la falta de efectividad de los recursos de la jurisdicción interna constituyó un trato cruel. Además, el hecho de no haber dado digna sepultura a los restos de Bámaca Velásquez tiene hondas repercusiones en la cultura maya a la que éste pertenecía, "por la relevancia central que tiene en su cultura el vínculo activo que une a los vivos con los muertos, pues la falta de un lugar sagrado donde acudir para velar por este nexo constituye una preocupación profunda que brota de los testimonios de muchas comunidades mayas. ${ }^{35}$

En estos casos la Corte señala que la imposibilidad del ritual genera la intensificación del sufrimiento padecido por los parientes; ello implica establecer que el Estado incumple sus obligaciones internacionales al no contribuir a la búsqueda y posterior entrega de los cuerpos, pues con dicha omisión se produce la vulneración a la integridad personal, consagrada en el Art. $5^{\circ}$ de la Convención.

33 Blake vs Guatemala (1998), párrafo 115

34 Blake vs. Guatemala (1998), párrafo 115.

35 Bámaca Velásquez vs. Guatemala (2000), párrafo 145. 


\subsection{Una distinción que vale la pena realizar}

De la exposición de los casos fue posible percibir el trato dado por la Corte Interamericana a la integridad personal de los familiares de víctimas de vulneraciones de derechos. Ante ello, el presente apartado pretende señalar una prevención a dicho trato y proponer uno alternativo.

Es importante señalar que si bien la Corte realiza una labor importante al vincular la imposibilidad de dar sepultura a los restos con la vulneración a la integridad personal de los deudos, su aporte es parcial toda vez que al tratar el daño causado por la imposibilidad de rituales mortuorios, o por el inadecuado trato a los restos póstumos, lo hace sólo de modo accesorio a la desaparición, como factor que incrementa el dolor y angustia de los deudos, sin advertir que se trata de dos situaciones distintas.

Una primera situación es la vulneración a la integridad personal de los familiares de detenidos desaparecidos que se manifiesta en la angustia que les causa la desaparición forzada de su ser querido. Otra situación, diversa, es aquella vulneración a la integridad personal de los deudos generada por la imposibilidad de realizar rituales mortuorios conducentes a permitir el duelo. Ambas situaciones implican diferentes daños los cuales se diferencian en temporalidad, fuentes y mecanismos de reparación.

En cuanto a la temporalidad, el daño que genera la angustia por la desaparición de un ser querido se produce en cuanto se toma conocimiento de su ausencia, manteniéndose mientras se desconozca su paradero; esto implica decir que el daño se ha generado en el pasado, con el acto que provoca la desaparición. En cambio, la imposibilidad de celebrar ritos fúnebres provocada por la falta de restos óseos del ser querido genera un daño permanente y actual, el cual se ejecuta en el presente y se mantiene mientras no se entregue el cuerpo de aquel que ha fallecido o se realicen ritos simbólicos que permitan el duelo. ${ }^{36}$

En cuanto a las fuentes, el primero de los daños tiene su causa en el acto que genera la desaparición, ${ }^{37}$ mientras que el segundo de los daños se produce por la falta de entrega de osamentas que impide llevar a cabo ritual fúnebre alguno.

36 Estos ritos simbólicos pueden ser diversos, podrían producirse entierros de pertenencias del fallecido, reconocimiento y disculpas por parte de las autoridades, memoriales, etc.; pero siempre deberían estar acompañados de la posibilidad de conocer las reales circunstancias que rodearon la muerte del detenido desaparecido ya que ello permite un restablecimiento del derecho a la verdad.

37 En nuestro contexto, normalmente se debió a actos de violencia estatal, como es el caso de las desapariciones forzadas como práctica habitual de las dictaduras latinoamericanas. 
Respecto al modo de poner término al daño y mecanismos de reparación, ${ }^{38} \mathrm{el}$ daño que implica la imposibilidad de efectuar el rito fúnebre solo cesa con la entrega de las osamentas del ser querido o, con la realización de rituales simbólicos que, por equivalencia, permitan concluir adecuadamente el duelo. En cuanto a su reparación ella podría producirse de diversas formas tanto indemnizatorias como tendientes a la revelación de la verdad histórica. Por otro lado, el daño que genera la desaparición, al tener su fuente en un acto realizado en el pasado, ha cesado pero resta su reparación. Dicha reparación es principalmente pecuniaria ya que junto a la angustia y temor de la desaparición suelen existir daños patrimoniales. ${ }^{39}$

Si la Corte adoptara la distinción propuesta sería un gran avance ya que, tal como esta investigación propone, la vulneración a la integridad personal de los familiares de detenidos desaparecidos proviene del malestar psíquico y emocional que implica un proceso de duelo defectuoso o inacabado, como consecuencia de un rito fúnebre que no se efectúa ante la imposibilidad de contar con los restos óseos del fallecido. Esto conlleva una forma de reparación propia y específica, distinta a las que se han planteado para compensar aquellos daños derivados de la desaparición, ya que solo podría cesar el daño con la correcta identificación y entrega de las osamentas a los deudos. $\mathrm{O}$, ante la absoluta imposibilidad de dicha entrega, mediante rituales simbólicos y acceso a la información relativa a las circunstancias en que se produce la muerte del desaparecido; lo que permitiría esclarecer la verdad histórica.

\section{ANÁLISIS DEL GASO GHILENO}

El golpe militar del 11 de septiembre de 1973 puso fin al gobierno del Presidente Salvador Allende dando lugar a un período dictatorial que se extendió hasta el 11 de marzo de 1990. Recuperada la democracia, el Presidente Patricio Aylwin creó la Comisión Nacional de Verdad y Reconciliación (Rettig), ${ }^{40}$ cuyo principal objetivo era contribuir al esclarecimiento de la verdad sobre las violaciones a los derechos humanos cometidas durante la dictadura militar. ${ }^{41}$ En su informe, se establece la recepción de 3.550 denuncias sobre personas ejecutadas o desaparecidas, acogiéndose

38 Estimo que la cesación del daño y su reparación son diversos. Se pone término al daño cuando se deja de realizar aquel acto que lo genera, mientras que la reparación es una medida que busca compensar el daño sufrido. Es posible poner término a un daño sin repararlo, pero no parece posible reparar mientras el daño siga produciéndose. En el tema estudiado, solo podría cesar el daño la entrega de los cuerpos y la realización del rito fúnebre efectivo o simbólico, mientras que la reparación se daría una vez detenido el daño y podría, o no, bastarse a sí misma con el acto de la entrega. Ello dependerá del caso a caso, toda vez que podría haber quienes exijan medidas reparatorias y otros que se sientan satisfechos con la sola entrega o realización de actos simbólicos tendientes al acceso al derecho a la verdad.

39 Un ejemplo de ello serían los casos en que quien es desaparecido era el proveedor del grupo familiar, lo que deja al resto de la familia en un claro desamparo económico, que suele compensarse en términos de empobrecimiento efectivo sufrido por la familia.

40 Decreto Supremo No 355 (1990)

41 Mayores antecedentes en http://www.ddhh.gov.cl/ddhh_rettig.html. Para una revisión del impacto del Informe de la Comisión en la sociedad chilena, véase FerRara (2015). 
2.296 como casos calificados. Buscando suplir los vacíos, el año 2003 se crea la Comisión Nacional sobre Prisión Política y Tortura (Valech) ${ }_{2}^{42}$ cuyo informe fue dado a conocer el 28 de noviembre de 2004 y en año 2009 la Comisión Asesora Presidencial para la Calificación de Detenidos Desaparecidos, Ejecutados Políticos y Víctimas de Prisión Política y Tortura, cuyo informe fue dado a conocer el 18 de agosto de 2011. El Estado de Chile ha reconocido oficialmente a 40.018 víctimas de violaciones a los derechos humanos, de los cuales 3.065 fueron ejecutados o son detenidos desaparecidos. Según el Balance 2014 del Programa de Derechos Humanos del Ministerio del Interior, el total de causas que permanecen abiertas en el país por crímenes de lesa humanidad ocurridos durante la dictadura cívico-militar asciende a 1.045. ${ }^{43}$

Nuestro Estado ha impulsado diversas políticas de reparación de las víctimas, incluyendo reparaciones para los familiares de detenidos desaparecidos, ${ }^{44}$ por ejemplo: a) Pensión de reparación, la cual consiste en una cantidad de dinero mensual; b) Beca de educación para los hijos (subsidio mensual de 1,24 UTM durante los 10 meses lectivos del año; c) Atención gratuita en salud para el grupo familiar (a través del programa PRAIS del Ministerio de Salud); d) Exención del Servicio Militar Obligatorio para los hijos de las víctimas, ${ }^{45}$ e) Beneficios complementarios, tales como la incorporación en Cajas de Compensación, beneficios de asignación por muerte, condonación de deudas en el Fondo Solidario de Crédito Universitario y Bono de Reparación para los hijos (ascendiente a 10 millones de pesos). ${ }^{46}$ Pese a lo anterior, no cabe duda que el principal mecanismo de reparación consiste en la identificación y entrega de las osamentas de los detenidos desaparecidos a sus familiares.

Tal como se señala en el capitulo anterior es posible distinguir entre la identificación y entrega de los cuerpos del desaparecido y las demás medidas de reparación. Mientras las otras medidas son una forma de compensar en parte los daños sufridos por los familiares, la entrega de los cuerpos de detenidos desaparecidos pone fin a la vulneración a la integridad personal que se sigue produciendo mientras no sea posible que los familiares procesen correctamente el duelo. La identificación y entrega de los restos es una medida doblemente reparadora: pone término a un daño que de manera permanente afectaba a los familiares al permitirles efectuar el rito fúnebre y el duelo; y contribuye al reconocimiento del derecho a la honra, del derecho al acceso a la justicia y del derecho a la verdad tanto respecto de los familiares como del propio detenido desaparecido.

Lo anterior, sin tener en cuenta los casos en que se ha incurrido en errores en la identificación de los restos. El 2002 fue dado a conocer el Informe Glasgow, en el cual se informaba que al menos tres, de veinte, identificaciones de detenidos desaparecidos realizadas por el Servicio Médico Legal eran incorrectas. En marzo de 2005,

42 Decreto $\mathrm{N}^{\circ} 1.040$ (2003).

43 Mayores antecedentes en http://www.ddhh.gov.cl/filesapp/balanceprensa.pdf.

44 Ley $\mathrm{N}^{\circ} 19.123$ (1992) y Ley $\mathrm{N}^{\circ} 19.980$ (2004).

45 Art. 40 del Decreto Ley No 2.306 (1978).

46 Mayores antecedentes en http://www.ddhh.gov.cl/social_beneficios.html. 
el ministro Sergio Muñoz dio la orden de exhumar 96 restos enterrados en el Patio 29 del Cementerio General y periciarlos con la aplicación de la técnica de ADN mitocondrial. El resultado fue dramático: de las 96 víctimas del Patio 29, fueron mal identificadas 48, no existe seguridad de la identidad de otras 37 , en cuatro casos no hubo resultados, otros tres cuerpos no fueron periciados ya que sus restos se encontraban fuera del país, no hubo muestras de ADN en otros tres y en un caso el ADN no está acreditado ${ }^{47}$. El problema se produjo porque a la época de realización de las primeras identificaciones ejecutadas por el Servicio Médico Legal la técnica utilizada era el reconocimiento morfológico. Técnica consistente en comparar características físicas conocidas de la persona desaparecida con huellas corporales existentes en las osamentas, como la altura, complexión y alguna característica particular de quien se busca identificar. Con el avance de la tecnología se adquirió una nueva técnica identificatoria correspondiente al análisis del ADN mitocondrial. En estos casos se comparan muestras provenientes de los restos esqueléticos con muestras aportadas por los familiares de la persona desaparecida.

El Estado ha incurrido en dos graves falencias en materia de identificación y entrega de osamentas de detenidos desaparecidos. En primer lugar, el porcentaje de identificación y entrega a los familiares de los restos de los detenidos desaparecidos es bajísimo, quedando más del $90 \%$ de los casos pendientes. Todavía se desconoce la identidad de un número considerable de osamentas o el paradero de personas desaparecidas. En segundo lugar, 48 víctimas fueron mal identificadas. En esos casos los familiares ejecutaron el ritual funerario, pero con posterioridad se les informó que la identificación era errónea. Fue necesario exhumar los restos de estas personas, reabriendo las heridas del pasado. Una vez más los familiares no han podido esclarecer la verdad de lo sucedido a sus seres queridos, no les han podido dar sepultura ni han podido llevar a cabo el proceso de duelo, todo lo cual vulnera nuevamente su integridad personal.

\section{Caso Dávila García ${ }^{48}$}

Los tribunales han reconocido la responsabilidad del Estado por falta de servicio en la incorrecta identificación del detenido desaparecido Luis Dávila García. Los demandantes - la madre y hermanos- expresan que Luis fue detenido el 15 de octubre de 1973, desconociéndose su paradero hasta el 28 de octubre de 1994, oportunidad en la cual sus restos les fueron entregados por funcionarios del Servicio Médico Legal. Dicha institución determinó que uno de los cuerpos exhumados del Patio 29 del Cementerio General correspondía a Dávila García, estableciéndose como fecha de su muerte el 26 de octubre de 1973. Sin embargo, el 21 de abril de 2006 se les comunicó que los restos que les habían sido entregados no correspondían a los de su familiar, quien pasaba a ser nuevamente un detenido desaparecido. Evidentemente,

47 OSORIO (2006).

48 La elección de este caso se debe en primer lugar a la relevancia mediática que este tuvo; asimismo, permite evidenciar la falta de diligencia a la hora de identificar los restos de los detenidos desaparecidos, lo que denuncia una clara falta de voluntad política tendiente al efectivo esclarecimiento de la verdad histórica. 
este hecho les produjo un daño moral y psicológico considerable. El Poder Judicial estableció la responsabilidad por falta de servicio en sentencia pronunciada el 29 de agosto de 2012; condenando al Estado de Chile a indemnizar a la madre con una suma ascendiente a 80 millones de pesos, y a cada uno de los hermanos por un monto de 20 millones de pesos. En el Considerando $4^{\circ}$ de la sentencia de la Corte Suprema se reconoce el daño que provoca en los familiares la revelación que el cuerpo fuera identificado erróneamente:

[...] que la falta de servicio en que incurrió el Servicio Médico Legal significó un evidente perjuicio o daño moral a los familiares del fallecido Luis Herminio Dávila García, quienes permanecieron por un importante período de tiempo convencidos de que los restos de su pariente eran efectivamente los que les habían sido entregados el 28 de octubre de 1994 con el consiguiente dolor provocado al conocer las causas del fallecimiento que se consignaron en el certificado de defunción del occiso, dolor y sufrimiento que vivieron doblemente al tomar conocimiento que la identificación había sido errónea, circunstancia que sin duda para una madre implica perder un familiar en dos ocasiones y respecto del cual todavía se desconoce su paradero. ${ }^{49}$

En el fallo se reconoce la responsabilidad del Estado y se hace referencia al daño y dolor que provoca dicha situación a los familiares. Cabe mencionar que la Corte no vincula el daño provocado a la familia con la vulneración a su derecho a la integridad personal. ${ }^{50}$

El Estado ha incumplido sus obligaciones internacionales al no adoptar todas las medidas a su alcance para identificar adecuadamente los restos que han sido encontrados y entregarlos a sus familiares. Según lo dispuesto en el art. $1^{\circ}$ de la Convención Americana, los Estados partes se comprometen a respetar los derechos y libertades reconocidos en ella y a garantizar su libre y pleno ejercicio. En consecuencia, si el Estado de Chile no entrega a los familiares los cuerpos de los detenidos desaparecidos correctamente identificados, incurre en una vulneración a su derecho a la integridad personal.

\section{GONGLUSIONES Y PROPUESTAS}

Se ha procurado mostrar la interdependencia que existe entre rito fúnebre, duelo y luto. Se ha argumentado que la imposibilidad de llevar a cabo el rito fúnebre impide el duelo y el luto de los familiares y seres queridos de la persona desaparecida. Los familiares son también víctimas, pues la ausencia del ser querido atenta contra su integridad personal. El Estado debe hacer todo lo que esté a su alcance para identificar los cuerpos de los detenidos desaparecidos y entregarlos a sus familiares. De lo contrario, los deudos no podrán realizar el correspondiente ritual mortuorio prolongándose en el tiempo su dolor y la angustia.

49 Dávila García con Fisco (2013).

50 Es precisamente por ello que es relevante esta investigación, ya que el reconocimiento del daño por parte de la Corte debió traducirse en la identificación del derecho afectado, pero ello no ocurrió ni ha ocurrido aún en nuestra jurisprudencia. 
La integridad personal se encuentra reconocida en el Art. $5^{\circ}$ de la Convención Americana de Derechos Humanos. Si el Estado no procura buscar los cuerpos de los detenidos desaparecidos, estaría desatendiendo sus obligaciones internacionales. El Estado no sólo tiene responsabilidad por los hechos ilícitos cometidos por sus agentes, sino que también vulnera los derechos de los familiares de las víctimas cuando no procura identificar los restos de los detenidos desaparecidos o realiza dicha identificación de forma negligente.

Tal como se señala en el capítulo III letra c, si bien la Corte Interamericana realiza una importante contribución al reconocer, en primer lugar, que los familiares de las víctimas de violaciones de DDHH pueden ser también víctimas y que, existe una relación entre la integridad personal de estos familiares de desaparecidos y el trato que reciben los restos póstumos de sus seres queridos; se estima que tal contribución es imperfecta debido a que podría ser mayor si se reconociera que existen dos problemáticas diversas: en primer lugar la ausencia misma del desaparecido la cual genera dolor y angustia a sus familiares y, en segundo lugar, la vulneración del derecho a la integridad personal de los deudos que implica la imposibilidad de realización de rituales mortuorios como consecuencia de una inexistente o errónea identificación de restos óseos. Entender tal diferencia permite comprender que diversas problemáticas requieren soluciones diversas; mientras en el primer caso la indemnización aparece como una forma válida de reparación, en el segundo es insuficiente toda vez que el daño no cesa mientras no se produzcan las correctas identificaciones que permitan la realización del rito fúnebre o los rituales simbólicos que permitan a sus familiares cerrar el ciclo inacabado del duelo.

Deben desarrollarse políticas públicas que solucionen de manera definitiva la problemática de la identificación de los restos que han sido exhumados. El Estado debe asumir la importancia que tiene para los familiares la posibilidad de enterrar a sus muertos, pues si ello no sucede se vulnera su integridad.

Junto con fortalecer los organismos especializados en la identificación de los restos de detenidos desaparecidos, no se deben descartar las acciones judiciales que puedan interponer los familiares en contra de quienes han vulnerado su integridad personal. La forma en que entendamos dicho derecho puede hacer la diferencia ya que nuestros tribunales no hacen un reconocimiento expreso a este derecho de los deudos de las víctimas de violaciones a DD.HH. Esta posibilidad debe estudiarse ya que, tal como se aprecia en el caso Dávila García, los tribunales reconocen el daño que produce la incorrecta identificación de restos óseos pero no lo han relacionado con la vulneración a un derecho de rango fundamental como lo es la integridad personal. Asimismo, las políticas públicas deben incorporar esta noción, permitiendo que más casos sean objeto de protección y medidas de reparación. 


\section{BIBLIOGRAFÍA CITADA}

Afanador, María Isabel (2002). "El Derecho a la Integridad Personal. Elementos para su análisis", Convergencia. Revista de Ciencias Sociales No 9(30), septiembre-diciembre, pp. 147-164.

Aldunate, Eduardo (2008). Derechos Fundamentales (Legal Publishing).

ARIÉs, Philippe (2000). Historia de la muerte en Occidente. Desde la edad media hasta nuestros días (Acantilado).

Brown, Donald E (1991): Human Universals (McGraw Hill).

Ferrara, Anita (2015). Assessing the Long-term Impact of Truth Commissions. The Chilean truth and reconciliation commission in historical perspective (Routledge).

García, Gonzalo y Contreras, Pablo (2014). "Diccionario Constitucional Chileno", Cuadernos del Tribunal Constitucional, $\mathrm{N}^{\mathrm{o}} 55$.

LiRA, Elizabeth (2015). "Derechos Humanos y Fundamentos de la Paz Social", Revista Mensaje, octubre, pp. 10-13.

Nash, Claudio (2014). "Artículo 5. Derecho a la Integridad Personal", en Steiner, Christian y URIBe, Patricia (eds.), Convención Americana sobre Derechos Humanos. Comentario (Konrad Adenauer Stiftung), pp. 131-160.

Nogueira, Humberto (2007). "Los derechos contenidos en tratados de derechos humanos como parte del parámetro de control de constitucionalidad: la sentencia. Rol No 786-2007 del Tribunal Constitucional", Estudios Constitucionales, Vol. $5 N^{\circ} 2$, pp. 457-466.

NogueIra, Humberto (2015): "El bloque constitucional de derechos en Chile, el parámetro de control y consideraciones comparativas con Colombia y México: Doctrina y jurisprudencia", Estudios Constitucionales, Vol. 13 Nº 2, pp. 301-350.

Osorio, Víctor (2006): “El escándalo del Patio 29: Los errores de identificación”, Revista Ercilla, $\mathrm{N}^{\circ} 3.293$, 8-21 de mayo de 2006, disponible en http://www.ercilla.cl/ web/index2.php?option=com_content\&do_pdf $=1 \& i d=350$.

SuÁrez Rienda, Verónica (2011). "Ciencia y religión: visiones y manejo emocional de la muerte y el duelo", Revista de Humanidades, 18, diciembre, pp. 49-64.

Thomas, Louis-Vincent (1983): Antropología de la muerte (Fondo de Cultura Económica).

Tribunal Constitucional (2011). Recopilación de Furisprudencia del Tribunal Constitucional (1981-2011). Colección Conmemoración de 40 años del Tribunal Constitucional.

Van Gennep, Arnold (2008). Los ritos de paso (Alianza). 


\section{NORMAS GITADAS}

\section{Sistema Interamericano:}

Convención Americana sobre Derechos Humanos, 1969, Pacto de San José de Costa Rica

Convención Interamericana sobre Desaparición Forzada de Personas, 1994.

\section{Chile:}

Ley No 2.306 (Ministerio de Defensa Nacional), Promulgada el 2 de agosto de 1978 y publicada en el D.O. el 12 de septiembre de 1978, sobre Reclutamiento y Movilización de las Fuerzas Armadas.

Decreto No 873 (Ministerio de Relaciones Exteriores), promulgado el 23 de agosto de 1990 y publicado en el D.O. el 5 de enero de 1991, aprueba Convención Americana sobre Derechos Humanos.

Ley N 19.123 (Ministerio del Interior), promulgada el 31 de enero de 1992 y publicada en el D.O. el 8 de febrero de 1992, Crea Corporación Nacional de Reparación y Reconciliación, Establece Pensión de Reparación y Otorga Otros Beneficios en Favor de Personas que Señala,

Ley $\mathrm{N}^{\circ} 19.980$ (Ministerio del Interior), promulgada el 24 de octubre de 2004 y publicada en el D.O. el 9 de noviembre de 2004, modifica la Ley $\mathrm{N}^{\circ}$ 19.123, Ley de Reparación, Ampliando o Estableciendo Beneficios en Favor de las Personas que Indica.

Decreto $N^{\circ}$ 100, promulgado el 17 de septiembre de 2005, Constitución Política de la República de Chile. 


\section{JURISPRUDENCIA CITADA}

\section{Chile:}

Caicheo Barrientos c/Pérez Santana (2012). Corte de Apelaciones de Punta Arenas (Recurso de protección), 16 de agosto de 2012.

Dávila García con Fisco (2013). Corte Suprema (recurso de casación en el fondo), 16 de mayo de 2013.

Llaguel Figueroa y otros c/Ilustre Municipalidad de Santiago y otros (2014). Corte de Apelaciones de Santiago, Recurso de protección, 18 de agosto de 2014.

Muñoz c/ Muñoz (2009). Tribunal Constitucional, Requerimiento de inaplicabilidad por inconstitucionalidad, 29 de septiembre de 2009.

Gómez con Universidad de la República (2009). Primer Juzgado de Letras del Trabajo de Santiago, Tutela laboral, 29 de noviembre de 2009, MJJ22291.

Rivera con Vida Tres (2010). Juzgado de Letras del Trabajo de Valparaíso, Tutela laboral, 19 de marzo de 2010, MJJ23460.

Villegas Paillán c/ Georgia Díaz (2010). Corte de Apelaciones de Coyhaique, Recurso de apelación, 25 de agosto de 2010.

Zapata con Taleb (2015). Juzgado de Letras del Trabajo de San Bernardo, Tutela laboral, 20 de marzo de 2015, MJJ40676.

\section{Corte Europea de Derechos Humanos:}

Çakici v. Turkey (1999). Corte Europea de Derechos Humanos, 8 de julio de 1999.

Timurtas v. Turkey (2000). Corte Europea de Derechos Humanos, de 13 de junio 2000.

\section{Corte Interamericana de Derechos Humanos:}

Aloeboetoe y otros vs. Surinam (1993). Corte Interamericana de Derechos Humanos, 10 de septiembre de 1993

Blake versus. Guatemala (1998). Corte Interamericana de Derechos Humanos, 24 de Enero de 1998.

Villagrán Morales y otros vs. Guatemala (1999). Corte Interamericana de Derechos Humanos, 19 de Noviembre de 1999.

Bámaca Velásquez versus. Guatemala (2000). Corte Interamericana de Derechos Humanos, 25 de Noviembre de 2000.

Juan Humberto Sánchez vs. Honduras (2003). Corte Interamericana de Derechos Humanos, 7 de junio de 2003.

Masacre Plan de Sánchez versus Guatemala (2004). Corte Interamericana de Derechos Humanos, 29 de abril de 2004.

Kawas Fernández vs. Honduras (2009). Corte Interamericana de Derechos Humanos, 3 de abril de 2009. 